\title{
Consciência ambiental: um estudo empírico da capacidade preditiva de variáveis psicográficas e sociodemográficas
}

Este artigo teve como objetivo identificar a consciência ambiental de uma amostra da população sul-mato-grossense, por meio de variáveis psicográficas e sócio demográficas. Os conceitos teóricos foram testados em uma amostra significativa de 844 docentes e discentes de uma universidade brasileira, empregando-se técnicas estatísticas de regressão linear múltipla para poder explicar a relação da variável latente da consciência ambiental, com as demais variáveis explicativas, considerando a sua intensidade preditiva. Os resultados mostraram que existem diferenças significativas de consciência ambiental ente os grupos avaliados Destacou-se que a variável psicográfica efetividade percebido do meio ambiente tem maior poder de explicar a consciência ambiental. As variáveis sociodemográficas indicam que os com idade acima de 24 anos e os docentes relatam uma maior consciência ambiental. Não existem diferenças significativa quanto a faixa de renda familiar. 0 estudo apresenta o seu valor acadêmico por retratar os comportamentos ambientais de uma parcela da população, podendo colaborar com outras pesquisas e indicar ações para a melhoria da percepção ambiental.

Palavras-chave: Preocupação Ambiental; Efetividade Percebida; Educação Ambiental; Altruísmo Ecológico; Ativismo Político.

\section{Environmental awareness: an empirical study of the predictive capacity of psychographic and sociodemographic variables}

\begin{abstract}
This article aimed to identify the environmental awareness of a sample of the population of Mato Grosso do Sul, through psychographic and socio-demographic variables. The theoretical concepts were tested in a significant sample of 844 teachers and students from a Brazilian university, using statistical techniques of multiple linear regression to be able to explain the relationship of the latent variable of environmental awareness, with the other explanatory variables, considering its intensity predictive. The results showed that there are significant differences in environmental awareness among the groups evaluated. It was highlighted that the psychographic variable effectiveness perceived by the environment has a greater power to explain environmental awareness. Sociodemographic variables indicate that those over the age of 24 and teachers report greater environmental awareness. There are no significant differences in terms of family income. The study presents its academic value for portraying the environmental behaviors of a portion of the population, being able to collaborate with other research and indicate actions to improve environmental perception.
\end{abstract}

Keywords: Environmental Concern; Perceived Effectiveness; Environmental Education; Ecological Altruism; Political Activism.

Topic: Desenvolvimento, Sustentabilidade e Meio Ambiente

Reviewed anonymously in the process of blind peer
Received: 03/03/2021

Approved: 26/03/2021

Jeferson de Paula Almeida (ic)

Universidade Anhanguera, Brasil

http://lattes.cnpq.br/5069615257048989

http://orcid.org/0000-0002-9741-233X

Jeferson paula almeida@hotmail.com

José Francisco dos Reis Neto

Universidade Anhanguera, Brasil

http://lattes.cnpq.br/9069806202978279

http://orcid.org/0000-0002-1152-1149

jfreisneto@terra.com.br

Celso Correia de Souza (iD

Universidade Anhanguera, Brasil

http://lattes.cnpq.br/2881392515816773

http://orcid.org/0000-0002-2689-8264

csouza939@gmail.com

Referencing this:

ALMEIDA, J. P.; REIS NETO, J. F.; SOUZA, C. C.. Consciência ambiental: um estudo empírico da capacidade preditiva de variáveis psicográficas e sociodemográficas. Revista Ibero Americana de Ciências Ambientais, v.12, n.3, p.481-491, 2021. DOI:

http://doi.org/10.6008/CBPC2179-6858.2021.003.0039 


\section{INTRODUÇÃO}

Os impactos antrópicos negativos causados ao meio ambiente fizeram com que homem começasse a modificar seus hábitos comportamentais em relação ao meio ambiente, inclusive, buscando a origem dos produtos que são consumidos por ele e a sua família, valorizando o cultivo dos mesmos sem agrotóxicos e fertilizantes químicos, produtos que podem causar danos ao meio ambiente. Assim, surge um novo tipo de consumidor, que visa à qualidade de vida, preocupado com os preceitos ambientais, entendidos como consciência ambiental, preocupação ambiental, efetividade percebida, ativismo político e altruísmo ecológico.

Este artigo apresenta um estudo da consciência ambiental dos indivíduos nas dimensões psicográficas (efetividade percebida, preocupação ambiental, ativismo político e altruísmo ecológico) e sócio demográficas (idade e renda). Pode-se definir a consciência ambiental como a tendência de um indivíduo em se posicionar frente aos assuntos relativos ao meio ambiente de uma maneira a favor ou contra. Assim, indivíduos com maiores níveis de consciência ambiental tenderiam a tomar decisões levando-se em consideração o impacto ambiental de suas posturas e ações (BEDANTE et al., 2004). Sob o ponto de vista social, este comportamento da consciência ambiental está sendo mais desejável (ANDO et al., 2015), como uma ação antropocêntrica.

A efetividade percebida (EP) é entendida, neste contexto, como o julgamento íntimo do indivíduo que impacta nos problemas ambientais. São as formas de perceber o ambiente em que se está inserido e o seu entorno, podendo, o indivíduo, contribuir de forma positiva ou negativa para a manutenção e preservação desse ambiente (TUAN, 2012; MELAZO, 2005).

A preocupação ambiental ( $p a)$ é a consciência única do ser humano com as causas ambientais e seu ato em participar das soluções que possam contribuir com a preservação desse espaço. A consciência ambiental do indivíduo é fundamental no processo de evolução do homem no que se refere à preocupação com o ambiente e seu entorno, pois, quando manifestada de forma negativa, grandes impactos negativos são identificados no meio ambiente (CHAN et al., 2000). A preocupação ambiental se tornou algo importante a partir da mudança de paradigmas da sociedade em relação à visão do homem para com o ambiente que o cerca. A evolução de alguns conceitos também foi fundamental para que a preocupação ambiental se tornasse relevante (RUDEK et al., 2007).

$\mathrm{O}$ ativismo político (AP), ou orientação política, atua no comportamento do indivíduo tornando-o ambientalmente e ecologicamente amigável. "Existe uma relação positiva entre as pessoas com maior visão política liberal e a consciência ambiental, do que as pessoas com uma visão política mais conservadora" (STRAUGHAN et al., 1999).

O altruísmo ecológico (AE) é o comportamento solidário do indivíduo com relação à preocupação com bem-estar do próximo, no entanto, se negativo, corresponde ao egoísmo do ser humano, resultando na exploração do meio ambiente. Assim, o altruísmo conduz a intensidade da consciência ambiental, se positivo, produz a construção de comportamentos solidários ambientais e sociais do indivíduo, se negativo, 
desenvolve atitudes no ser humano capaz de compreender o mundo do ponto de vista exclusivo de seu próprio interesse (LENCASTRE, 2010; GASPAR, 2014).

O objetivo principal deste trabalho foi identificar o nível da consciência ambiental, por meio de variáveis psicográficas e sócio demográficas, dos docentes e discentes das áreas das ciências sociais, humanas e exatas de uma Instituição de Ensino Superior (IES), localizada na cidade de Campo Grande, MS.

Como objetivos específicos deste estudo pode-se destacar: avaliar a percepção da consciência ambiental dos grupos dos docentes e discentes das áreas das ciências pesquisadas na IES; identificar as relações significativas de predição da consciência ambiental em relação às variáveis latentes explicativas da efetividade percebida sobre a preocupação ambiental de discentes e docentes da IES e; avaliar a consciência ambiental, a efetividade percebida, o altruísmo ecológico e o ativismo político por meio de variáveis sócio demográficas como faixa etária e renda familiar de professores e alunos da IES.

\section{METODOLOGIA}

A pesquisa teve uma abordagem quantitativa, de natureza básica e explicativa, com levantamento bibliográfico nacional e internacional sobre a consciência ambiental e assuntos correlatos, com o intuito de aprofundar o conhecimento teórico e empírico. A sustentação teórica da literatura científica proporcionou a elaboração e adequação de questionário, empregando a escala de concordância de Likert de 7 pontos, sendo 1 para discordar totalmente até 7 para concordar totalmente com a declaração. 0 questionário foi aplicado em uma amostra por conveniência, em docentes e discentes de uma IES em Campo Grande, MS.

Procedeu-se a verificação da possível existência de dados atípicos. De tal forma que esses dados pudessem dar consistência às variáveis latentes da consciência ambiental e das demais variáveis explicativas como: preocupação ambiental, efetividade percebida, ativismo político, altruísmo ecológico.

Para a determinação da dependência da variável latente da consciência ambiental (ca) das demais variáveis latentes explicativas foi utilizada a análise de regressão linear múltipla. A equação (1) representa o modelo geral de regressão multivariada.

$$
c a_{i}=\beta_{0}+\left(\beta_{1} \cdot e p_{i}\right)+\left(\beta_{2} \cdot p a_{i}\right)+\left(\beta_{3} \cdot a e_{i}\right)+\left(\beta_{4} \cdot a p_{i}\right)+E_{i}
$$

Onde: $c a_{i}$ é a variável consciência ambiental do fenômeno em estudo; $b_{0}$ é o intercepto (coeficiente linear; valor de y quando todas as variáveis explicativas forem iguais a zero); $b_{0}, b_{1}, b_{2}, b_{3} e b_{4}$ são os coeficientes das variáveis

explicativas; $e p_{i}$ a variável explicativa sobre a efetividade percebida do indivíduo $i ; p a_{i}$ a variável explicativa sobre a preocupação ambiental do indivíduo i; $a e_{i}$ a variável explicativa sobre altruísmo ecológico do indivíduo i; $a p_{i}$ a variável explicativa ativismo ou orientação política do indivíduo i; e $E_{i}$ o erro aleatório relativo ao indivíduo i, considerando que $\mathrm{i}=1,2,3, \ldots, \mathrm{n}$ e $\mathrm{n}=$ número de indivíduos da amostra.

As confiabilidades internas das variáveis latentes explicativas $\left(e p_{i}, p a_{i}, a e_{i}\right.$ e $\left.a p i\right)$ foram determinadas pelo alfa de Cronbach, precedendo-se à aplicação de análise fatorial exploratória.

A amostra foi constituída de 65 docentes e 779 discentes, perfazendo um total de 844 entrevistados. Segundo o critério de Hair Junior et al. (2009) para a análise fatorial exploratória e para uma análise de regressão linear múltipla, a amostra pode ser considerada como aceitável para este estudo. As análises estatísticas do segmento sociodemográfico, utilizou-se do teste t de Student, para a comparação das médias das variáveis independentes, para os constructos dos grupos de docentes/discentes, representados por 
renda familiar e faixa etária, para explicar e quantificar a variável latente da consciência ambiental e as demais variáveis latentes explicativas.

A discussão dos resultados se deu considerando-se que as variáveis psicográficas: ep como descrevendo os sentidos necessários e fundamentais no processo de percepção dos indivíduos e das suas sensações relacionadas ao ambiente, como seu habitat (MELEZO, 2005); ca como a construção de uma ética ambiental, que exige a intervenção das ciências com apelo preponderante para valores de preservação (SOARES et al., 2004); pa pelo desenvolvimento sustentável e planejamento das cidades, entendido como a harmonização entre desenvolvimento socioeconômico e conservação do meio ambiente (RUDEK et al., 2007); ae pelas emoções sociais e à racionalidade cognitiva do homem com o ambiente que o cerca (LENCASTRE, 2010) e; ap como um possível prognosticador do comportamento ecologicamente amigável (STRAUGHAN et al., 1999).

\section{RESULTADOS E DISCUSSÃO}

O questionário foi aplicado no primeiro semestre do ano letivo de 2017. O total de respondentes correspondeu a 844 indivíduos. Entre as observações havia 41,70\% de homens e 58,30\% de mulheres, deste total entre homens e mulheres havia $29,38 \%$ da área de ciências humanas, 38,15\% de ciências sociais aplicadas, 21,68\% de ciências exatas e 10,79\% de outras ciências. A Tabela 1 apresenta os resultados das variáveis sociodemográficas de docentes e discentes da IES, em Campo Grande - MS, ano de 2017

Tabela 1: Perfil sócio demográfico de discentes e docentes de uma IES.

\begin{tabular}{|c|c|c|c|c|c|}
\hline \multirow[b]{2}{*}{ Variável } & \multirow[b]{2}{*}{ Categoria } & \multicolumn{2}{|l|}{ Discente } & \multicolumn{2}{|l|}{ Docente } \\
\hline & & Frequência & $\%$ & Frequência & $\%$ \\
\hline \multirow{3}{*}{ Grau de Formação acadêmica } & Especialização & 0 & $0,0 \%$ & 23 & $35,4 \%$ \\
\hline & Mestrado & 0 & $0,0 \%$ & 28 & $43,1 \%$ \\
\hline & Doutorado & 0 & $0,0 \%$ & 14 & $21,5 \%$ \\
\hline \multirow{4}{*}{ Área de conhecimento da formação acadêmica } & Exatas & 167 & $21,4 \%$ & 16 & $24,6 \%$ \\
\hline & Humanas & 233 & $29,9 \%$ & 15 & $23,1 \%$ \\
\hline & Sociais Aplicadas & 296 & $38,0 \%$ & 26 & $40,0 \%$ \\
\hline & Outras Ciências & 83 & $10,7 \%$ & 8 & $12,3 \%$ \\
\hline \multirow{2}{*}{ Faixa etária } & De 18 a 24 anos & 530 & $68,0 \%$ & 1 & $1,5 \%$ \\
\hline & Acima de 24 anos & 249 & $32,0 \%$ & 64 & $98,4 \%$ \\
\hline \multirow{2}{*}{ Renda familiar } & Até $\mathrm{R} \$ 4200$ & 633 & $81,3 \%$ & 10 & $15,3 \%$ \\
\hline & Acima de $R \$ 4201$ & 146 & $18,7 \%$ & 55 & $84,6 \%$ \\
\hline
\end{tabular}

\section{Análise de Correlação de Pearson}

Em primeiro lugar foram analisados os dados atípicos observados na amostra coletada pelo método dos valores da distância de Mahalanobis, considerando as quatro variáveis independentes e o valor crítico de 18,47 (PALLANT, 2016). Da amostra de 844 discentes e docentes foram retirados 8 entrevistados que apresentaram valores acima do crítico, perfazendo, assim, 836 entrevistados.

As estatísticas de tolerância $(<0,18)$ e VIF (Variance Inflation Fator $>10)$ indicam a não existência de multicolinearidade. $O$ coeficiente de determinação $R^{2}$ indica que o modelo em análise explica $28,2 \%$ da variância. A estatística $F(4,831)=81,576, p<0,001)$ indica que o modelo, como um todo, é significativo, ou 
seja, existe pelo menos um beta diferente de zero. Portanto, rejeita-se a hipótese $\mathrm{H}_{0}$ de que todos os coeficientes $B_{i}(i=0,1,2,3,4)$ são iguais a zero. A Tabela 2 apresenta os coeficientes padronizados da Regressão Múltipla Hierárquica, na previsão da consciência ambiental. Usa-se a regressão múltipla hierárquica quando se quer testar o impacto de variáveis de previsão específica, enquanto controla a influência de outras. A análise de regressão hierárquica permite ao pesquisador especificar a ordem em que as variáveis são inseridas no processo. Essa análise fornece ao pesquisador o quão importante é uma variável específica para prever um resultado desejado.

\section{Análise das Variáveis Latentes Explicativas Psicográficas}

Analisando a Tabela 2, nota-se que a Efetividade Percebida possui os coeficientes de regressão significativos a $p<0,001$ nos três segmentos (Todos, Discentes e Docentes), explicando que existe correlação entre a efetividade percebida $(e p)$ e a consciência ambiental $(c a)$. Resultado semelhante também foi encontrado por (ROBERTS et al., 1997).

Tabela 2: Coeficientes não padronizados da Regressão Múltipla Hierárquica na previsão da Consciência Ambiental.

\begin{tabular}{llll}
\hline Variáveis Latentes & Todos & Discentes & Docentes \\
\cline { 2 - 2 } Constante & 0,527 & 0,409 & 2,743 \\
Efetividade Percebida $(e p)$ & $0,559^{* * *}$ & $0,528^{* * *}$ & $0,600^{* * *}$ \\
Preocupação Ambiental $(p a)$ & $0,033^{\mathrm{ns}}$ & $0,042^{\mathrm{ns}}$ & $-0,017^{\mathrm{ns}}$ \\
Altruísmo Ecológico $(a e)$ & $0,121^{*}$ & $0,149^{* *}$ & $-0,056^{\mathrm{ns}}$ \\
Ativismo Político $(a p)$ & $0,086^{*}$ & $0,096^{* *}$ & $-0,114^{\mathrm{ns}}$ \\
$\mathrm{F}$ (Ficher) & $81,576^{* * *}$ & $78,931^{* * *}$ & $4,216^{* *}$ \\
$\mathrm{R}^{2}$ (Coeficiente de determinação) & 0,282 & 0,290 & 0,219 \\
\hline
\end{tabular}

Legenda: ${ }^{\text {ns: }}$ não significativa; *significativa a $p<0,10 ;{ }^{* *}$ significativa a $p<0,05 ;{ }^{* *}$ significativa a $p<0,001$.

Pode-se inferir que a $(e p)$, para o grupo dos discentes, que apresenta um coeficiente de 0,528 e p<0,001, mostra que o estudo da percepção ambiental é de fundamental importância para que se possa compreender melhor as inter-relações entre o homem e o ambiente, suas expectativas, anseios, satisfações e insatisfações, julgamentos e condutas, concordando com os resultados de (FERNANDES et al., 2003).

Para o grupo de docentes, a variável (ep) apresenta um coeficiente de 0,600 e p<0,001, explicando que na medida em que suas estruturas de sensibilidade e cognitivas vão se transformando, transforma sua forma de olhar, percebendo os espaços com novas imagens e valores adquiridos com a interação com o ambiente a partir de novas lentes de observação (PANCERI, 1997).

Os resultados apresentados, dos grupos analisados, explicam que a variável Efetividade Percebida afeta positivamente a variável dependente Consciência Ambiental, ou seja, discentes e docentes têm o hábito de perceber o ambiente que se está inserido, aprendendo a proteger e a cuidar do mesmo (FAGGIONATO, 2002).

A variável ( $p a)$ possui os coeficientes de regressão não significativos nos três segmentos analisados, contrariando a teoria de Chan et al. (2000), de que a preocupação ambiental é considerada como a consciência individual com os problemas ambientais e a sua disposição em participar da solução, como um preditor da consciência ambiental. 
Pode-se inferir que, para o grupo dos discentes, que apresenta um coeficiente de $0,042^{\text {ns }}$, mostra que esta categoria analisada não se preocupa com os três princípios básicos do desenvolvimento sustentável, sendo: a conservação dos sistemas ecológicos sustentadores da vida e da biodiversidade, a garantia da sustentabilidade que utilizam recursos renováveis e o de manter as ações humanas dentro da capacidade de carga dos ecossistemas sustentadores, preconizado por (RUDEK et al., 2007).

Para o grupo de docentes, a variável ( $p a)$ apresenta um coeficiente de $\left(0,017^{\text {ns }}\right)$, intuindo que os indivíduos desse grupo não se importam que os seus comportamentos de compra têm impacto direto em muitas questões ambientais (DIAMANTOPOULOS et al., 2003). Pode-se compreender que a variável Preocupação Ambiental afeta negativamente a variável dependente Consciência Ambiental, ou seja, os dois grupos analisados não podem ser caracterizados, como rotula (D'SOUZA et al., 2007), como consumidores "verdes", ou seja, altamente preocupados com o ambiente.

A variável (ae) possui os coeficientes de regressão significativos a $p<0,10$, explicando que esse sentimento está na base de comportamentos pró-sociais e pró-ambientais importantes, que implicam a cooperação e a confiança nos outros, como afirma (LENCASTRE, 2010). Pode-se inferir que para o grupo dos discentes, apresenta um coeficiente de $0,149, p<0,05$, explicando que os alunos não se importam com os comportamentos que podem contribuir para compreender a natureza humana e desenvolver intervenções fomentando condutas pró-sociais, como também concluiu em sua pesquisa (GOUVEIA et al., 2014).

Para o grupo de docentes, a variável altruísmo ecológico $(a e)$ apresenta um coeficiente de $\left(0,056^{\text {ns }}\right)$, não significativo, demonstrando que os indivíduos não precisam ter consciência da ação para se comportar de forma egoísta ou altruísta (CHEDIAK, 2003). Os resultados obtidos de discentes e docentes, explicam que a variável ae afeta negativamente a variável dependente $(c a)$, apontando que os dois grupos não se importam com os princípios éticos em ambiente, como para a educação e para os valores ambientais (LENCASTRE, 2010).

A variável ap possui os coeficientes de regressão significativos a $p<0,10$, confirmando a teoria proposta por Straughan et al. (1999), de que as orientações políticas do indivíduo atuam como um possível prognosticador do comportamento ecologicamente amigável.

Pode-se inferir que para o grupo dos discentes, a variável ap apresenta um coeficiente de 0,096, $p<0,05$, apontando que os alunos possuem um dos dois ou os dois frames típico do ativismo ambientalista. O "conservacionista" que define o meio ambiente exclusivamente como mundo natural selvagem, vendo qualquer intervenção nele como questão técnica, restrita aos cientistas naturais, ou o frame "ecologia política" que inclui o mundo urbano na definição do problema ambiental (ALONSO, 2007a).

Para o grupo de docentes a variável ap apresenta um coeficiente $\left(0,114^{\text {ns }}\right)$, não significativo, explicando que não se importam se a causas da degradação ambiental são atribuídas ao desenvolvimento capitalista e ao estilo de vida moderno (DIANI, 1995). Nesta última variável, verifica-se que o resultado encontrado pelo grupo de discentes contribui de forma positiva para a variável dependente consciência ambiental $c a$, explicando que a ideia de meio ambiente é redefinida como relação entre grupos sociais e 
recursos naturais (ALONSO et al., 2007b). Já o resultado encontrado pelo grupo de docentes, aponta que esta variável afeta negativamente a variável dependente $c a$, ou seja, não existe relação entre ativismo político e consciência ambiental.

\section{Análise das Variáveis Latentes Explicativas Sócio Demográfica}

Foram analisadas três características socioeconômicas dos respondentes: tipo de atividade desenvolvida, faixa de idade e renda familiar de discentes e docentes de uma IES, em Campo Grande, ano de 2017. As categorias faixa de idade e renda familiar foram divididas em dois grupos, segundo a mediana da amostra. Assim, a faixa de idade foi dividida em um grupo com idade até 24 anos e outro acima de 24 anos. A renda familiar foi distribuída em um grupo com renda até $\mathrm{R} \$ 4.200,00$ e outro com renda superior a $\mathrm{R} \$$ 4.201,00 (referência monetária de julho de 2017), ambas com objetivo de permitir a análise de dois perfis sócios demográficos.

A Tabela 3 apresenta o perfil demográfico de discentes e docentes da IES da cidade de Campo Grande, investigada neste trabalho.

Tabela 3: Perfil demográficos de discentes e docentes de uma IES.

\begin{tabular}{|c|c|c|c|c|c|}
\hline \multirow[b]{2}{*}{ Variável } & \multirow[b]{2}{*}{ Categoria } & \multicolumn{2}{|l|}{ Discente } & \multicolumn{2}{|l|}{ Docente } \\
\hline & & Frequência & $\%$ & Frequência & $\%$ \\
\hline \multirow{2}{*}{ Faixa etária } & De 18 a 24 anos & 530 & $68,0 \%$ & 1 & $1,5 \%$ \\
\hline & Acima de 24 anos & 249 & $32,0 \%$ & 64 & $98,4 \%$ \\
\hline \multirow{2}{*}{ Renda familiar } & Até $\mathrm{R} \$ 4200$ & 633 & $81,3 \%$ & 10 & $15,3 \%$ \\
\hline & Acima de R\$ 4201 & 146 & $18,7 \%$ & 55 & $84,6 \%$ \\
\hline
\end{tabular}

Entre as observações havia $68,0 \%$ de discentes e 1,5\% de docentes com idades até 24 anos e $32 \%$ de discentes e 98,4\% de docentes acima de 24 anos e $81,3 \%$ de discentes e 15,3\% de docentes com rendas até $\mathrm{R} \$ \mathbf{4 . 2 0 0 , 0 0}$ e $18,7 \%$ de discentes e $84,6 \%$ de docentes com rendas superiores a $\mathrm{R} \$ 4.201,00$

\section{Análise das Variáveis Sociodemográficas}

Neste item foram analisadas as variáveis sociodemográficas, resultados do questionário em escala de concordância de Likert aplicado, com escala de 7 pontos, sendo 1 para discordar totalmente até 7 para concordar totalmente com a pergunta. Na Tabela 4 estão os resultados das médias e dos desvios-padrão para discentes e docentes da IES analisados sobre a consciência ambiental nas dimensões psicográfica da efetividade percebida, preocupação ambiental e ativismo político.

Tabela 4: Médias e desvios-padrão de discentes e docentes de uma IES sobre a consciência ambiental nas dimensões psicográficas.

\begin{tabular}{|c|c|c|c|c|}
\hline & \multicolumn{2}{|c|}{ Discente } & \multicolumn{2}{|c|}{ Docente } \\
\hline & Média & Desvio Padrão & Média & Desvio Padrão \\
\hline Consciência Ambiental & $4,30_{a}$ & 1,06 & $4,89_{b}$ & 0,85 \\
\hline Efetividade Percebida & $4,76_{a}$ & 0,89 & $5,09_{b}$ & 0,65 \\
\hline Preocupação Ambiental & $4,90_{a}$ & 0,76 & $4,87_{a}$ & 0,57 \\
\hline Altruísmo Ecológico & $4,62_{a}$ & 0,74 & $4,55_{a}$ & 0,68 \\
\hline Ativismo Político & $5,00_{a}$ & 1,00 & $4,99_{a}$ & 0,91 \\
\hline
\end{tabular}

Legenda: médias com as mesmas letras subscritas não possuem diferenças significativas ao nível de $p<0,05$; as médias 
com letras diferentes são significativamente diferentes a nível de $p<0,05$.

Pode-se inferir que para a variável $c a$ existem diferenças significativas entre as concordâncias indicadas pelos discentes e docentes. Os docentes apresentam maior valor médio de $c a$, possivelmente, relacionado ao seu maior nível de educação, em que lhes permitem demonstrar uma maior consciência na conservação da água, energia, compra para consumo e uso de produtos que menos contaminam o meio ambiente.

Pode-se inferir que, para a variável ep existem diferenças significativas entre as concordâncias indicadas pelos discentes e docentes. Os docentes apresentam maior valor médio de $e p$, demonstrando uma maior preocupação quanto ao papel de compra para consumo e a aquisição de produtos vendidos por empresas socialmente responsáveis.

As médias das variáveis $p a$, ae e ap não apresentam diferenças significativas, indicando que discentes e docentes possuem concordâncias semelhantes, sendo o ae responsável pelas "experiências emocionais do homem" (GASPAR, 2014), a PA pelas "mudanças da sociedade em relação à visão do homem para com o ambiente que o cerca" (RUDEK et al., 2007) e à variável ap pela "participação da sociedade civil em instâncias públicas" (DAGNINO, 1994).

Na Tabela 5 estão apresentados as médias e os desvios-padrão, por faixa etária, da consciência ambiental $(c a)$ em relação às variáveis psicográficas de discentes e docentes de uma IES de Campo Grande.

Tabela 5: Consciência ambiental em relação às variáveis psicográficas pelas faixas etárias de discentes e docentes de uma IES, em Campo Grande, ano de 2017.

\begin{tabular}{|c|c|c|c|c|}
\hline & \multicolumn{4}{|c|}{ Faixa Etária } \\
\hline & \multicolumn{2}{|c|}{ Até 24 anos } & \multicolumn{2}{|c|}{ Acima de 24 anos } \\
\hline & Média & Desvio Padrão & Média & Desvio Padrão \\
\hline Consciência Ambiental & $4,13_{a}$ & 1,04 & $4,70_{b}$ & 0,97 \\
\hline Efetividade Percebida & $4,68 \mathrm{a}$ & 0,90 & $4,96_{b}$ & 0,81 \\
\hline Preocupação Ambiental & $4,91_{a}$ & 0,75 & $4,87_{a}$ & 0,73 \\
\hline Altruísmo Ecológico & $4,59_{a}$ & 0,75 & $4,66_{a}$ & 0,72 \\
\hline Ativismo Político & $4,90_{a}$ & 0,98 & $5,15_{b}$ & 0,99 \\
\hline
\end{tabular}

Legenda: médias com mesmas letras subscritas não possuem diferenças significativas a $\mathrm{p}<0,05$; as médias com letras diferentes são significativamente diferentes a $p<0,05$.

Pode-se inferir, da Tabela 5, que para a variável ca existem diferenças significativas entre as concordâncias indicadas pelas pessoas com até 24 anos e acima de 24 anos. As pessoas acima de 24 anos apresentam maior valor médio de $c a$, possivelmente, relacionado a sua experiência de vida, em que lhes permitem demonstrar uma maior consciência na conservação de água e energia.

Nota-se da Tabela 5 que, para a variável ep existem diferenças significativas entre as concordâncias indicadas pelas pessoas com até 24 anos e acima de 24 anos. As pessoas acima de 24 anos apresentam maior valor médio de $e p$, demonstrando uma maior preocupação quanto ao comportamento do consumidor na compra de produtos vendidos por empresas socialmente responsáveis.

Ainda, da Tabela 5 pode-se notar que, para a variável ap existem diferenças significativas entre as concordâncias indicadas pelas pessoas com até 24 anos e acima de 24 anos. As pessoas acima de 24 anos apresentam maior valor médio de AP, possivelmente, segundo Alonso et al. (2007b) por saberem que a 
degradação ambiental é atribuída ao desenvolvimento capitalista e ao estilo de vida moderno.

As médias das variáveis $p a$ e ae não apresentaram diferenças significativas, indicando que discentes e docentes possuem concordância semelhantes, sendo à variável $a e$ responsável pelos sentimentos que estão na base de comportamentos pró-sociais e pró-ambientais importantes (LENCASTRE, 2010) e a variável pa pelo delineamento de estratégias que visem atingir este novo perfil do consumidor (ROBERTS, 1996).

$\mathrm{Na}$ Tabela 6 estão apresentados os resultados sobre a consciência ambiental de discentes e docentes de uma IES de Campo Grande em relação à renda familiar.

Tabela 6: Resultados sobre a consciência ambiental relativas às variáveis psicográficas em relação à renda familiar de discentes e docentes de uma IES, em Campo Grande, ano de 2017.

\begin{tabular}{|c|c|c|c|c|}
\hline & \multicolumn{4}{|c|}{ Renda Familiar } \\
\hline & \multicolumn{2}{|c|}{ Até $\mathrm{R} \$ \mathbf{4 . 2 0 0 , 0 0}$} & \multicolumn{2}{|c|}{ Acima de $\mathrm{R} \$ 4.201,00$} \\
\hline & Média & Desvio Padrão & Média & Desvio Padrão \\
\hline Consciência Ambiental & $4,33_{a}$ & 1,06 & $4,39_{a}$ & 1,02 \\
\hline Efetividade Percebida & $4,77_{a}$ & 0,88 & $4,81_{a}$ & 0,86 \\
\hline Preocupação Ambiental & $4,92_{a}$ & 0,76 & $4,84 a$ & 0,71 \\
\hline Altruísmo Ecológico & $4,64 a$ & 0,73 & $4,55_{a}$ & 0,75 \\
\hline Ativismo Político & $5,03_{a}$ & 1,02 & $4,88_{b}$ & 0,90 \\
\hline
\end{tabular}

Legenda: médias com mesmas letras subscritas não possuem diferenças significativas a $p<0,05$; as médias com letras diferentes são significativamente diferentes a $p<0,05$.

Pode-se inferir, da Tabela 6, que para a variável ap existem diferenças significativas entre as concordâncias indicadas em relação às rendas familiares de até $\mathrm{R} \$$ 4.200,00 e rendas familiares superior a $\mathrm{R} \$$ 4.201,00. As pessoas com rendas familiares de até $\mathrm{R} \$ 4.200,00$ apresentaram maior valor médio de $a p$, possivelmente, por compreenderem que a relação positiva entre as pessoas com maior visão política liberal e a consciência ambiental, do que as pessoas com uma visão política mais conservadora (STRAUGHAN et al., 1999). Observa-se, da Tabela 6, que as médias das variáveis latentes explicativas não apresentam diferenças significativas, indicando que discentes e docentes possuem concordância semelhantes.

\section{CONCLUSÕES}

O estudo psicográfico de discentes e docentes da IES de Campo Grande revela que os coeficientes da efetividade percebida( $(e p)$ de todos, docentes e discentes são significativos para a variável latente consciência ambiental $(c a)$. Os coeficientes da variável preocupação ambiental ( $p a$ ) de todos os indivíduos da amostra, docentes e discentes, não são significativos para análise e compreensão da variável $(c a)$. Os coeficientes da variável altruísmo ecológico $(a e)$ de todos os indivíduos da amostra são significativos para análise da variável $(c a)$; os coeficientes da variável $(a e)$ dos docentes e discentes não são significativos para compreender e analisar a variável $(c a)$. Os coeficientes de ativismo político $(a p)$, ou orientação política de todos e dos discentes são significativos para compreensão e análise da variável $(c a)$ e os coeficientes da variável ( $a p)$ dos docentes não significativos para compreender a variável $(c a)$ dos indivíduos. Assim, as variáveis psicográficas relacionadas à efetividade percebida da ação ambiental, a preocupação com o meio ambiente, o altruísmo ecológico e o ativismo ou orientação política de docentes e discentes podem ser 
utilizadas para compreensão e análise da consciência ambiental do indivíduo.

O estudo sócio demográfico revelou que a variável $(c a)$ apresenta uma maior média entre os docentes e para aqueles com mais de 24 anos, podendo-se intuir que o nível cultural e a idade mais avançada favorecem a consciência ambiental. Quanto às rendas familiares, não se observou diferenças significativas relativas à consciência ambiental. A variável $(e p)$ é um constructo com maior média para os indivíduos com mais de 24 anos, com percepções semelhantes entre docentes e discentes. Já, com relação à variável(ep), não apresentou diferenças significativas em relação à renda familiar.

As médias das variáveis $(p a)$ e $(a e)$ revelaram que são constructos que não apresentaram diferenças significativas quanto às características socioeconômicas dos respondentes (atividade desenvolvida, faixa de idade e renda familiar) e o ( $a p$ ) demonstrou que é um constructo que não apresenta diferenças significativas quanto às características socioeconômicas dos respondentes (atividade e faixa de idade), apresentando um maior ativismo entre aqueles com renda de até $\mathrm{R} \$ 4.200,00$.

Não foram desenvolvidos constructos para análise das médias sócio demográfica de gênero e sexo por não apresentarem valores significativos quanto as características socioeconômicas dos respondentes.

Desta forma, os resultados demonstraram que as variáveis latentes Efetividade Percebida $(e p)$, Preocupação Ambiental ( $p a)$, Altruísmo Ecológico $(a e)$ e Ativismo Político $(p a)$, atuam como um preditor da variável dependente Consciência Ambiental $(c a)$, apresentando diferenças significativas entre as constantes analisadas e que os constructos sócio demográficos de docentes/discentes, apenas duas variáveis puderam ser analisadas, a Consciência Ambiental $(c a)$ e a Efetividade Percebida (ep), demonstrando uma maior consciência na conservação de água, energia, compra e uma maior preocupação quanto ao papel de compra do consumidor e a aquisição de produtos vendidos por empresas socialmente responsáveis.

Assim, os resultados psicográficos e sócio demográficos dessa pesquisa podem contribuir de forma positiva para as Instituições de Ensino Superior, desenvolvendo programas e atividades com alunos e professores, demonstrando o impacto que ambos podem causar ao meio ambiente por meio de suas atitudes e comportamentos. Com isso, espera-se que discentes e docentes possam se tornar seres mais conscientes, capazes de se preocupar, perceber e promover o altruísmo ecológico e ambiental.

\section{REFERÊNCIAS}

ALONSO, A.; COSTA, V.; MACIEL, D.. O processo de formação da rede de ativismo ambientalista no Brasil. Movimentos Sociais, Participação e Democracia, Florianópolis, v.6, n.11, p.7-18, 2007a.

ALONSO, A.; COSTA, V.; MACIEL, D.. Identidade e Estratégia na Formação do Movimento Ambientalista Brasileiro. Revista Novos Estudos, São Paulo, n.79, p.151-167, 2007b.

ANDO, K.; YORIFUGITA, K.; OHNUMA, S.; MATTHIES, E.; KANBARA, A.. Transmitting pro-environmental behaviors to the next genration: a comparison between Germany and Japan. Asian Journal of Psychology, v.18, n.2, p.134-144, 2015. DOI: http://dx.doi.org/10.1111/ajsp.12078
BEDANTE, G. N.; SLONGO, L. A.. O comportamento de consumo sustentável e suas relações com a consciência ambiental e a intenção de compra de produtos ecologicamente embalados. In: EMA - ENCONTRO DE MARKETING, 6. Anais. Atibaia: Anpad, 2004

CHAN, R. Y. K.; LAU, L. B.. Y Antecedents of green purchases: a survey in China. Journal of Consumer Marketing, Bingley, v.17, p.338-357, 2000

CHEDIAK, K.. Notas Sobre a Concepção Evolucionista da Moral. Episteme, Porto Alegre, n.16, p.45-59, 2003. 
D `SOUZA, C.; TAGHIAN, M.; KHOSLA, R.. Examination of environmental beliefs and its impact on the influence of price, quality and demographic characteristics with respect to green purchase intention. Journal of Targeting, Measurement and Analysis for Marketing, Abingdon-onThames, v.15, n.2, p.69-78, 2007.

DAGNINO, E.. Sociedade civil e espaços públicos no Brasil. São Paulo: Paz e Terra/Unicamp, 1994.

DIAMANTOPOULOS, A.; SCHLEGELMICH, B. B.; SINKOVICS, R R.; BOHLEN, G. M.. Can socio-demographics still play a role in profiling green consumers? A review of the evidence and empirical investigation. Journal of Business Research, Indiana, v.56, n.2, p.465-480, 2003.

DIANI, M.. A structural analysis of the Italian environmental movement. In: Green networks. Edimburgo: Edinburgh University Press, 1995. p.35-47.

FAGGIONATO, S.. Percepção ambiental. São Paulo: USP, 2002.

FERNANDES, R. S.; SOUZA, V. J.; PELISSARI, V. B.; FERNANDES, S. T.. Uso da percepção ambiental como instrumento de gestão em aplicações ligadas às áreas educacional, social e ambiental. São Paulo: PUC, 2003.

GASPAR, A.. Neurobiologia e psicologia da empatia: pontos de partida para a investigação e intervenção da promoção da empatia. Campo Grande: Universidade Católica Portuguesa, 2014.

GOUVEIA, V. V.; SANTOS, W. S.; ATHAYDE, R. A. A.; SOUZA, R. V. L.; GUSMÃO, E. E. S.. Valores, altruísmo e comportamentos de ajuda: comparando doadores e não doadores de sangue. Psico, Porto Alegre, v.45, n.2, p.209218, 2014

HAIR JUNIOR, J. F.; BLACK, W. C.; BABIN, B. J.; ANDERSON, R. E.. Multivariate data analysis. 7 ed. Upper Saddle River: Prentice Hall, 2009.

LENCASTRE, M. P. A.. Bondade, Altruísmo e Cooperação. Considerações evolutivas para a educação e a ética ambiental. Lusófona de Educação, Lisboa, n.15, p.113-124, 2010 .

MELAZO, G. C.. Percepção Ambiental e educação ambiental: Uma Reflexão Sobre as Relações Interpessoais e Ambientais no Espaço Urbano. Olhares \& Trilhas, Uberlândia, v.6, n.6, p.45-51, 2005

PALLANT, J.. SPSS Survival Manual: a step-by-step guide to data analysis using IBM SPSS. 6 ed. London: Mc Graw Hill Education, 2016

PANCERI, B.. O campo do saneamento ambiental rural: estudo das percepções hábitos e gêneros na visão comunitária e institucional. Dissertação (Mestrado em Engenharia Ambiental) - Universidade Federal de Santa Catarina, Florianópolis, 1997.

ROBERTS, J. A.. Will the real socially responsible consumer please step forward?. Business Horizons, Indiana, v.39, p.7983, 1996

ROBERTS, J. A.; BACON, D. R.. Exploring the subtle relationship between environmental concern and ecologically conscious consumer behavior. Journal of Business Research, Amsterdã, v.40, n.1, p.79-89, 1997.

RUDEK, C. G.; MUZZILLO, C. S.. O início da abordagem ambiental nos planos de desenvolvimento urbano brasileiro a partir da preocupação mundial em busca do desenvolvimento sustentável. Akropólis, Umuarama, v.15, n.1-2, p.11-18, 2007.

SOARES, B. E. C.; NAVARRO, M. A.; FERREIRA, A. P.. Desenvolvimento sustentado e consciência ambiental: natureza, sociedade e racionalidade. Ciências \& Cognição, Rio de Janeiro, v.2, p.42-49, 2004.

STRAUGHAM, R. D.; ROBERTS, J.. Environmental segmentation alternatives a look at green consumer behavior in the new millennium. The Journal of Consumer Marketing, Bingley, v.16, n.6, p.558-575, 1999.

TUAN, Y.-F.. Topofilia: um estudo da percepção, atitudes e valores do meio ambiente. SciELO-EDUEL, 2012.

A CBPC - Companhia Brasileira de Produção Científica (CNPJ: 11.221.422/0001-03) detém os direitos materiais desta publicação. Os direitos referem-se à publicação do trabalho em qualquer parte do mundo, incluindo os direitos às renovações, expansões e disseminações da contribuição, bem como outros direitos subsidiários. Todos os trabalhos publicados eletronicamente poderão posteriormente ser publicados em coletâneas impressas sob coordenação da Sustenere Publishing, da Companhia Brasileira de Produção Científica e seus parceiros autorizados. Os (as) autores (as) preservam os direitos autorais, mas não têm permissão para a publicação da contribuição em outro meio, impresso ou digital, em português ou em tradução. 